\title{
VIII. Proposed improvement of the hygrometer
}

\section{J. Berzelius}

To cite this article: J. Berzelius (1809) VIII. Proposed improvement of the hygrometer , Philosophical Magazine Series 1, 33:129, 39-42, DOI: 10.1080/14786440908562819

To link to this article: http://dx.doi.org/10.1080/14786440908562819

$$
\text { 曲 Published online: } 18 \text { May } 2009 .
$$

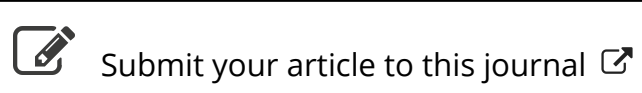

Џll Article views: 2

Q View related articles $\sqsubset$ 


\section{Proposed Improvement of the Hygrometer. By J. Berzeluus*.}

Dalton's admirable researches luave at last decided the dispute respecting the water of the atmosphere, which had lasted for nearly a whole century. The least absurd of the ideas advanced on the subject was, that the water became dissolved by the air, much in the manuer as other solid bodies are dissolved by water, and that the aqueous meteors depended on alterations in the solvent capacity of the air, whereby the water is sometimes precipitated, producing clouds and rain, and at times dissolved, producing exhalations.

But Dalton has proved, that the water of the atmosphere is independent of the air; and that if the earth were deprived of the latter, it would nevertheless be surrounded by aqueous vapour, the extent of which would depend upon the degree of heat only; its increase in an increase of temperature being rather hindered than promoted by the air. The water contained in the air is in a gasiform state, mixed with the atmospheric air, just as in this the oxygen is mixed with the nitrogen, or as water is mixed with any other fluid. The quantity of water-gas in the air (as we have said) is in proportion to the temperature; and if the latter were immutable, the former would also continue the same; but perpetual changes of situations, circumstances, and temperature, produce continual alterations in this gas of the air, and from this alone are most of the aqueous meteors derived. Dalton, by a series of experiments, has calculated the quantity of water capable of maintaining a gasiform state, correspondent with every degree of the thermometer; and in a separate table determined these quantities according to the different columns of mercury they support. For instance, at $-15^{\circ}+$ it is equivalent to a column of 0.064 inches, at $-5^{\circ}$ to 0.120 , at $0^{\circ}$ to 0.183 , at $+15^{\circ}$ to 0.422 , at $+50^{\circ}$ to 2.90 , and at the boiling point to 25.0 inches, and this in vacuo as well as in the open air. But it seldom bappens

* Translated from Berzelius's Philosophical Journal, 1808.

t What Thermometer does M. Berzelius use? EorT.

C 4 
that the air is charged with water to the maximum of its temperature- a circumstance which renders the indications of the hygrometer highly useful and necessary. The hygrometer should express-To what column of mercury the water.gas of the air corresponds? and at the same time determine the absolute quantity of the gas; and, the temperature of the air being known-How much of this gas it can take up beyond what it already bolds, and how soon the exhalation thereof can take place? Our usual hygrometers of hair, and of whalebone, are, in this respect, very imperfect : the results from them are not much to be relied on, having always a relation to the temperature in which the examination is made.

Dalton made use of a very plain instrument for his hygrometrical essays : he filled a long cylindrical glass vessel with cold well water, and when the dew appeared to coat the outside, he decanted the water, and wiped the glass well with linen, after which he returned the water, and this he repeated until the glass ceased to appear moist upon the introduction of the water; when he, by means of the thermometer, examined the temperature of the water so poured in : he then found the degree of heat at which the air might prove saturated (if I might so say) with the contained water-gas, and in consulting his tables he learned what column of mercury coincided therewith, he being already acquainted with the temperature of the air. This simple apparatus served all his purposes.

We nevertheless may easily sec, that although this method is built upon a true principle, yet it will prove to be both inconvenient, tedions, and defective, as the precise temperature at which the glass should cease to appear moist cannot possibly be atraincd. Therefore, to obtain a greater certainty in the result, though scarcely with less trouble, $I$ altered Dalton's plan in the following manner :

Let us supposc tinat the air which we are about to examine is at $20^{\circ}$, and that a glass of ordinary spring water, generally at $7^{\circ}$ when recently taken from the spring, is bedewed in this air. 'The difference between the temperature of the air and the water is then equal to $13^{\circ}$. Should we take 
12 glass vessels, in the first of which we mix 12 parts of this spring water with one part of water which has acquired the temperature of the air; in the second, 11 parts of the former with two of the latter, and so in a decreasing ratio throughout, we then obtain fluids which differ from each other by one degree of temperature. Of these we examine the first which does not bedew, and its temperature then precisely indicates the expansive capacity of the water-gas of the air. Should the air happen to be too dry, so as not to yield a deposition of water, then we might render it cooler by the addition of sal ammoniac which dissolves in it ; and in winter we can increase the cold by snow, with salt or sal ammoniac. But even this method is slow and troublesome for hygrometrical investigations. I therefore determined to precipitate the water from the air by the thermometer itself, as follows :

The bulb, defended by a case of oiled silk, being immersed in the cold water, was taken up after having acquired the temperature of the water. It then became covered with vapour of water; I observed also the degree of the thermometer when the dew disappeared, and found the expansive capacity of the water-gas, according to Dalton's tables, tolerably near. But $I$ also found that a very damp air at $+18^{\circ}$ to $+20^{\circ}$ produced a somewhat greater result than what it ought to be, because the thermometer, when much water is deposited on its bulb, proceeds little beyond the true point before all is evaporated. Besides, there is another circumstance which renders the use of the ordinary thermometer less certain, that, namely, a small portion of deposit is not accurately distinguished on the bulb. I therefore caused a thermometer bulb of steel to be made, greatly oblongated, its outside highly polished, and thereto attached a steel tube an inch long, wherein I closely cemented a thermometer tube, and made thereof an actual thermometer. This instrument completely answered my purpose. When the bulb with its oil case was immersed in the cooling mixture, and taken up as the mercury fell an inch, or every other inch according to circumstances, I at last arrived at a period when the bulb became covered with a quickly-passing 
coat of aqueous vapour, and the scale then expressed the degree of expansive capacity of the water-gas of the air with the greatest precision possible. This kind of hygrometer, besides the nicety of its results, also has the advantage that an experiment may be made without loss of time and trouble, and does not tire the observator like the former methods.

IX. Materials for a History of the Prussiates. By $M$. Proust *.

Part SeCond.

Some Precipitations by the simple Prussiate.

$T_{H I s}$ prussiate yields, with metallic solutions, results different from those of the triple prussiate. Scheele had already remarked some of them, and the following came under my observation :

Silver. Triple prussiate: a white precipitate which soon became blue, on account of the white prussiate of iron which is mixed with that of silver.

Silver. Simple prussiate : a white curd which does not change.

Gold. Triple prussiate : nothing.

Gold. Simple : white precipitate, which becomes of a fine yellow.

If we heat the mixture, this precipitate, when heated, does not fulminate; it is a true prussiate of gold. When heated in a retort, it gives water, abundance of empyreumatic oil, carbonic acid gas, which burns with a blue flame, and a residue of gold mixed with charcoal powder. Upon looking over my notes I do not find ammonia mentioned, perhaps from neglect.

Molyldic Acid and Oxide of Tungsten.-The two prussiates yielded nothing in either of these cases.

Titanium. Triple prussiate: Prussian blue proceeding from the iron always retained by this oxide.

* From Annales de Chimie, tome lx. p. 225.-For M. Proust's first paper, see the preceding volume.

Titanium. 